\title{
HUBUNGAN ANTARA HIMPUNAN KUBIK ASIKLIK DENGAN RECTANGLE
}

\author{
SISKA NURMALA SARI \\ Program Studi Matematika, \\ Fakultas Matematika dan Ilmu Pengetahuan Alam, Universitas Andalas, \\ Kampus UNAND Limau Manis Padang, Indonesia, \\ siska.nurmala95@yahoo.com
}

\begin{abstract}
Abstrak. Dalam artikel ini akan dipelajari hubungan antara himpunan kubik asiklik dengan rectangle. Diberikan suatu kubus dasar $Q$ yang merupakan suatu hasil kali berhingga dari interval-interval dasar $I=[l, l+1]$ atau $I=[l, l]$ untuk suatu $l \in \mathbb{Z}$. suatu himpunan kubik $X$ adalah gabungan berhingga dari kubus-kubus dasar $Q$. Himpunan kubik dengan bentuk $X=\left[k_{1}, l_{1}\right] \times\left[k_{2}, l_{2}\right] \times \cdots \times\left[k_{n}, l_{n}\right] \subset \mathbb{R}^{n}$ disebut rectangle, dimana $k_{i}, l_{i}$ adalah bilangan bulat dan $k_{i} \leq l_{i}$. Selanjutnya diperoleh bahwa sebarang rectangle $X$ adalah asiklik, dengan kata lain $H_{k}(X)$ isomorfik dengan $\mathbb{Z}$ jika $k=0$, dan $H_{k}(X)$ isomorfik dengan 0 jika $k>0$.
\end{abstract}

Kata Kunci: Himpunan kubik, asiklik, isomorfik

\section{Pendahuluan}

Topologi merupakan cabang matematika yang merupakan pengembangan dari geometri. Sesuai dengan namanya, topologi, kajian awal bidang ini adalah dengan mempertimbangkan konsep 'tempat' dalam struktur lokal maupun globalnya (konsep ruang topologi).

Misalkan diberikan ruang topologi $X$. Selanjutnya didefinisikan suatu objek aljabar $H_{*}(X)$ yang disebut dengan homologi dari $X$, dimana secara topologi $H_{*}(X)$ adalah suatu invarian, artinya jika $X$ dan $Y$ adalah homeomorfik maka $H_{*}(X)$ dan $H_{*}(Y)$ adalah isomorfik,

$$
X \approx Y \Rightarrow H_{*}(X) \cong H_{*}(Y) .
$$

$H_{*}(X)$ merupakan koleksi dari grup homologi ke-k dari $X$ yang dinotasikan dengan $H_{k}(X)$.

Tulisan ini difokuskan pada homologi kubik, dimana ruang topologi dapat direpresentasikan sebagai suatu kubik. Suatu kubus dasar $Q$ adalah suatu hasil kali hingga dari interval-interval dasar $I=[l, l+1]$ atau $I=[l, l]$ untuk suatu $l \in \mathbb{Z}$. Jadi, $Q=I_{1} \times I_{2} \times \cdots \times I_{n} \subset \mathbb{R}^{n}$. Himpunan kubik merupakan suatu kelas khusus dari ruang topologi.

Salah satu jenis dari himpunan kubik adalah himpunan kubik asiklik, dimana homologi dimensi ke- $k$ adalah

$$
H_{k}(X) \cong \begin{cases}\mathbb{Z}, & \text { jika } \mathrm{k}=0, \\ 0, & \text { selainnya. }\end{cases}
$$


Himpunan kubik dengan bentuk $X=\left[k_{1}, l_{1}\right] \times\left[k_{2}, l_{2}\right] \times \cdots \times\left[k_{n}, l_{n}\right] \subset \mathbb{R}^{n}$ disebut rectangle, dimana $k_{i}, l_{i}$ adalah bilangan bulat dan $k_{i} \leq l_{i}$. Rectangle juga dapat dikatakan sebagai kubus dasar jika $k_{i}=l_{i}$ atau $k_{i}+1=l_{i}$ untuk setiap $i$. Tulisan ini bertujuan untuk mengkaji hubungan antara himpunan kubik asiklik dengan rectangle.

\section{Hubungan Antara Himpunan Kubik Asiklik dengan Rectangle}

Definisi 2.1. [1] Rectangle adalah suatu himpunan dengan bentuk $X=\left[k_{1}, l_{1}\right] \times$ $\left[k_{2}, l_{2}\right] \times \cdots \times\left[k_{n}, l_{n}\right] \subset \mathbb{R}^{n}$, dimana $k_{i}, l_{i}$ adalah bilangan bulat dan $k_{i} \leq l_{i}$.

Sebarang rectangle adalah himpunan kubik. Rectangle juga dapat dikatakan sebagai kubus dasar jika $k_{i}=l_{i}$ atau $k_{i}+1=l_{i}$ untuk setiap $i$.

Teorema 2.2. [1] Sebarang Rectangle $X$ adalah asiklik.

Bukti. Misalkan $\Delta=[k, l] \subset \mathbb{R}$ suatu interval dengan titik ujung bilangan bulat dan didefinisikan

$$
\mu(\Delta):= \begin{cases}l-k, & \text { jika } l>k, \\ 1, & \text { jika } k=l .\end{cases}
$$

Interval $\Delta$ merupakan interval dasar jika dan hanya jika $\mu(\Delta)=1$.

Misalkan $X$ suatu rectangle, sehingga dapat ditulis sebagai

$$
X=\Delta_{1} \times \Delta_{2} \times \cdots \times \Delta_{d},
$$

dimana $\Delta_{i}=\left[k_{i}, l_{i}\right]$ merupakan interval dengan titik ujung bilangan bulat. Didefinisikan

$$
\mu(X):=\mu\left(\Delta_{1}\right) \mu\left(\Delta_{2}\right) \cdots \mu\left(\Delta_{d}\right) .
$$

Untuk setiap $m$ akan dibuktikan rectangle $X$ adalah asiklik, yaitu dengan menggunakan induksi terhadap $m:=\mu(X)$.

- Untuk $m=1$.

Jika $m=1$ maka $X$ merupakan kubus dasar. Oleh karena itu, $X$ asiklik berdasarkan Teorema $2.76[1]$.

- Untuk $m>1$.

Asumsikan bahwa $X$ adalah asiklik untuk semua $\mu(X)<m$. Karena $m>1$ maka $\mu\left(\Delta_{i_{0}}\right)=l_{i_{0}}-k_{i_{0}} \geq 2$ untuk suatu $i_{0} \in\{1,2, \cdots, d\}$. Misalkan diberikan sebarang rectangle

$$
\begin{aligned}
X & :=\left[k_{1}, l_{1}\right] \times \cdots \times\left[k_{i_{0}}, l_{i_{0}}\right] \times \cdots \times\left[k_{d}, l_{d}\right], \\
X_{1} & :=\left[k_{1}, l_{1}\right] \times \cdots \times\left[k_{i_{0}}, k_{i_{0}}+1\right] \times \cdots \times\left[k_{d}, l_{d}\right], \\
X_{2} & :=\left[k_{1}, l_{1}\right] \times \cdots \times\left[k_{i_{0}}+1, l_{i_{0}}\right] \times \cdots \times\left[k_{d}, l_{d}\right] .
\end{aligned}
$$

Akibatnya diperoleh

$$
X_{1} \cap X_{2}=\left[k_{1}, l_{1}\right] \times \cdots \times\left[k_{i_{0}}+1\right] \times \cdots \times\left[k_{d}, l_{d}\right]
$$


adalah suatu rectangle dan

$$
\begin{aligned}
& \mu\left(X_{1}\right)=\mu\left(X_{1} \cap X_{2}\right)=\frac{\mu(X)}{\mu\left(\Delta_{i_{0}}\right)}<m, \\
& \mu\left(X_{2}\right)=\mu(X) \frac{\mu\left(\Delta_{i_{0}}\right)-1}{\mu\left(\Delta_{i_{0}}\right)}<m .
\end{aligned}
$$

Maka berdasarkan asumsi induksi diperoleh bahwa $X_{1}, X_{2}$, dan $X_{1} \cap X_{2}$ masingmasing adalah asiklik. Karena $\mu(X)=\mu\left(X_{1} \cup X_{2}\right)=m$ dan berdasarkan Teorema $2.78[1]$, maka $X$ adalah asiklik.

Pernyataan pada Teorema 2.2 tidak berlaku sebaliknya, yaitu tidak semua himpunan kubik yang asiklik adalah rectangle.

Contoh 2.3. Misal diberikan himpunan kubik

$$
\Gamma^{1}=[0,1] \times[0] \cup[0] \times[0,1] .
$$

Himpunan-himpunan dari kubus dasar adalah

$$
\begin{aligned}
& \mathcal{K}_{0}\left(\Gamma^{1}\right)=\{[0] \times[0],[0] \times[1],[1] \times[0]\}, \\
& \mathcal{K}_{1}\left(\Gamma^{1}\right)=\{[0,1] \times[0],[0] \times[0,1]\} .
\end{aligned}
$$

Maka basis untuk himpunan rantai-rantai dari kubus dasar adalah

$$
\begin{aligned}
\widehat{\mathcal{K}}_{0}\left(\Gamma^{1}\right) & =\{[\widehat{0] \times[0]}, \widehat{[0] \times[1]}, \widehat{[1] \times[0]}\}, \\
& =\{\widehat{[0]} \diamond \widehat{[0]}, \widehat{[0]} \diamond \widehat{[1]}, \widehat{[1]} \diamond \widehat{[0]}\}, \\
\widehat{\mathcal{K}}_{1}\left(\Gamma^{1}\right) & =\{[0, \widehat{1] \times[0]},[0] \times[0,1]\}, \\
& =\{\widehat{[0,1]} \diamond \widehat{[0]}, \widehat{[0]} \diamond \widehat{0,1}]\} .
\end{aligned}
$$

Untuk menghitung operator batas dari $\Gamma^{1}$, perlu dihitung batas dari anggotaanggota basisnya.

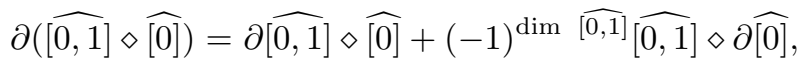

$$
\begin{aligned}
& =(\widehat{[1]}-\widehat{[0]}) \diamond \widehat{[0]}+(-1)^{1} \widehat{[0,1]} \diamond 0, \\
& =\widehat{[1]} \diamond \widehat{[0]}-\widehat{[0]} \diamond \widehat{[0]}-1(0) \text {, } \\
& =\widehat{[1]} \diamond \widehat{[0]}-\widehat{[0]} \diamond \widehat{[0]} \text {, } \\
& =-\widehat{[0]} \diamond \widehat{[0]}+\widehat{[1]} \diamond \widehat{[0]} \text {. }
\end{aligned}
$$

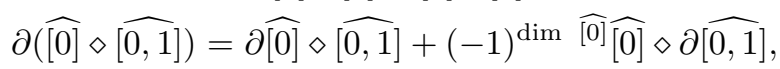

$$
\begin{aligned}
& =0 \diamond \widehat{[0,1]}+(-1)^{0} \widehat{[0]} \diamond(\widehat{[1]}-\widehat{[0]}) \text {, } \\
& =0+\widehat{[0]} \diamond(\widehat{[1]}-\widehat{[0]}) \text {, } \\
& =\widehat{[0]} \diamond \widehat{[1]}-\widehat{[0]} \diamond \widehat{[0]} \text {, } \\
& =-\widehat{[0]} \diamond \widehat{[0]}+\widehat{[0]} \diamond \widehat{[1]} \text {. }
\end{aligned}
$$


Selanjutnya, ditentukan basisnya

$$
\begin{aligned}
\partial(\widehat{[0,1]} \diamond \widehat{[0]}) & =-\widehat{[0]} \diamond \widehat{[0]}+\widehat{[1]} \diamond \widehat{[0]}, \\
& =-1(\widehat{[0]} \diamond \widehat{[0]})+0(\widehat{[0]} \diamond \widehat{[1]})+1(\widehat{[1]} \diamond \widehat{[0]})+0(\widehat{[1]} \diamond \widehat{[1]}) . \\
\partial(\widehat{[0]} \diamond \widehat{[0,1]}) & =-\widehat{[0]} \widehat{[0]}+\widehat{[0]} \diamond \widehat{[1]}, \\
& =-1(\widehat{[0]} \diamond \widehat{[0]})+1(\widehat{[0]} \diamond \widehat{[1]})+0(\widehat{[1]} \diamond \widehat{[0]})+0(\widehat{[1]} \diamond \widehat{[1]}) .
\end{aligned}
$$

Sehingga basis dari $\Gamma^{1}$ dapat ditulis dalam bentuk matriks

$$
\partial_{1}=\left[\begin{array}{cc}
-1 & -1 \\
0 & 1 \\
1 & 0
\end{array}\right] \text {. }
$$

Untuk memperoleh $Z_{1}\left(\Gamma^{1}\right)$, akan dicari ker $\partial_{1}$ dengan menyelesaikan persamaan

$$
\begin{aligned}
{\left[\begin{array}{l}
0 \\
0 \\
0
\end{array}\right] } & =\left[\begin{array}{cc}
-1 & -1 \\
0 & 1 \\
1 & 0
\end{array}\right]\left[\begin{array}{l}
\alpha_{1} \\
\alpha_{2}
\end{array}\right], \\
& =\left[\begin{array}{l}
-\alpha_{1}-\alpha_{2} \\
\alpha_{2} \\
\alpha_{1}
\end{array}\right],
\end{aligned}
$$

yang memberikan

$$
\alpha_{1}=\alpha_{2}=0 .
$$

Karena $Z_{1}\left(\Gamma^{1}\right)=0, B_{1}\left(\Gamma^{1}\right)=0$, akibatnya

$$
H_{1}\left(\Gamma^{1}\right) \cong 0 .
$$

Selanjutnya akan dihitung $H_{0}\left(\Gamma^{1}\right)$. Pertama-tama, amati bahwa tidak ada solusi untuk persamaan

$$
\left[\begin{array}{cc}
-1 & -1 \\
0 & 1 \\
1 & 0
\end{array}\right]\left[\begin{array}{l}
\alpha_{1} \\
\alpha_{2}
\end{array}\right]=\left[\begin{array}{l}
1 \\
0 \\
0
\end{array}\right] .
$$

Ini berimplikasi bahwa $\widehat{[0]} \diamond \widehat{[0]} \notin B_{0}\left(\Gamma^{1}\right)$. Dengan cara lain,

$$
\begin{aligned}
\partial(\widehat{[0,1]} \diamond \widehat{[0]}) & =-\widehat{[0]} \diamond \widehat{[0]}+\widehat{[0]} \diamond \widehat{[1]}, \\
\partial(\widehat{[0]} \diamond \widehat{[0,1]}) & =-\widehat{[0]} \diamond \widehat{[0]}+\widehat{[1]} \diamond \widehat{[0]} . \\
\partial(-\widehat{[0,1]} \diamond \widehat{[0]}+\widehat{[0]} \diamond \widehat{[0,1]}) & =-\partial(\widehat{[0,1]} \diamond \widehat{[1]})+\partial(\widehat{[0]} \diamond \widehat{[0,1]}) \\
& =-(-\widehat{[0]} \diamond \widehat{[0]}+\widehat{[1]} \diamond \widehat{[0]})-\widehat{[0]} \diamond \widehat{[0]}+\widehat{[0]} \diamond \widehat{[1]} \\
& =\widehat{[0]} \widehat{[0]}-\widehat{[1]} \diamond \widehat{[0]}-\widehat{[0]} \diamond \widehat{[0]}+\widehat{[0]} \diamond \widehat{[1]} \\
& =-\widehat{[1]} \diamond \widehat{[0]}+\widehat{[0]} \diamond \widehat{[1]} .
\end{aligned}
$$

Maka

$$
\{\widehat{[0]} \diamond \widehat{[0]}-\widehat{[0]} \diamond \widehat{[1]}, \widehat{[0]} \diamond \widehat{[0]}-\widehat{[1]} \diamond \widehat{[0]}, \widehat{[1]} \diamond \widehat{[0]}-\widehat{[0]} \diamond \widehat{[1]}\} \subset B_{0}\left(\Gamma^{1}\right)
$$


Khususnya, semua rantai-rantai dasar bersifat homologous, sehingga

$$
\widehat{[0]} \diamond \widehat{[0]} \sim \widehat{[0]} \diamond \widehat{[1]} \sim \widehat{[1]} \diamond \widehat{[0]} .
$$

Selanjutnya, misalkan sebarang rantai $z \in C_{0}\left(\Gamma^{1}\right)$. Maka

$$
z=\alpha_{1} \widehat{[0]} \diamond \widehat{[0]}+\alpha_{2} \widehat{[0]} \diamond \widehat{[1]}+\alpha_{3} \widehat{[1]} \diamond \widehat{[0]} .
$$

Sehingga pada tingkat homologi,

$$
\begin{aligned}
{[z]_{\Gamma^{1}} } & =\left[\alpha_{1} \widehat{[0]} \diamond \widehat{[0]}+\alpha_{2} \widehat{[0]} \diamond \widehat{[1]}+\alpha_{3} \widehat{[1]} \diamond \widehat{[0]}\right]_{\Gamma^{1}} \\
& =\alpha_{1}[\widehat{[0]} \diamond \widehat{[0]}]_{\Gamma^{1}}+\alpha_{2}[\widehat{[0]} \diamond \widehat{[1]}]_{\Gamma^{1}}+\alpha_{3}[\widehat{[1]} \diamond \widehat{[0]}]_{\Gamma^{1}} \\
& =\left(\alpha_{1}+\alpha_{2}+\alpha_{3}\right)[\widehat{[0]} \diamond \widehat{[0]}]_{\Gamma^{1}} .
\end{aligned}
$$

Oleh karena itu, setiap anggota dari $H_{0}\left(\Gamma^{1}\right)=Z_{0}\left(\Gamma^{1}\right) / B_{0}\left(\Gamma^{1}\right)$ dibangun oleh $\widehat{[0]} \widehat{\diamond[0]}$, dan karenanya $\operatorname{dim} H_{0}\left(\Gamma^{1}\right)=1$. Lebih khusus,

$$
H_{k}\left(\Gamma^{1}\right) \cong \begin{cases}\mathbb{Z}, & \text { jika } k=0,1, \\ 0, & \text { selainnya. }\end{cases}
$$

\section{Ucapan Terima kasih}

Penulis mengucapkan terima kasih kepada Bapak Dr. Admi Nazra, Ibu Dr. Yanita, Ibu Nova Noliza Bakar, M.Si, dan Bapak Budi Rudianto, M.Si yang telah memberikan masukan dan saran sehingga artikel ini dapat diselesaikan dengan baik.

\section{Daftar Pustaka}

[1] Kaczynski. T, K. Mischaikow, M. Mrozek. 2004. Computational Homology. Springer-Verlag New York. 